\title{
Risk Factors for the Progression of Chronic Kidney Disease in Children
}

\author{
Yo Han Ahn, M.D., Ph.D. \\ Hee Gyung Kang, M.D., Ph.D. \\ II-Soo Ha, M.D., Ph.D. \\ Department of Pediatrics, Seoul \\ National University College of \\ Medicine and Seoul National \\ University Children's Hospital; Kidney \\ Research Institute, Medical Research \\ Center, Seoul National University \\ College of Medicine, Seoul, Republic of \\ Korea
}

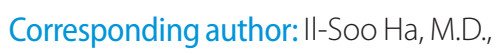

Received: 2 March 2021

Revised: 21 April 2021

Accepted: 5 June 2021

\begin{abstract}
This is an open-access article distributed under the terms of the Creative Commons Attribution Non-Commercial License (http:// creativecommons.org/licenses/by-nc/4.0/) which permits unrestricted non-commercial use, distribution, and reproduction in any medium, provided the original work is properly cited.
\end{abstract}

Chronic kidney disease (CKD) in children is associated with various complications, including poor growth and development, mineral bone disorder, cardiovascular disease, kidney failure, and mortality. Slowing down the progression of CKD is important since CKD is often not curable. Prospective cohort studies have been conducted to understand the progression and outcomes of CKD in children, and these studies have identified non-modifiable and modifiable risk factors. Recognition of known risk factors and early intervention are important to delay the progression of kidney function decline in children.

Key words: Chronic kidney disease, Risk factors, Children, Kidney failure

\section{Introduction}

Chronic kidney disease (CKD) is a growing public health problem worldwide with increasing incidence and prevalence ${ }^{1)}$. The prevalence of CKD in children is much lower than that in adults, ranging from 15 to 75 cases per 1 million children ${ }^{2}$. CKD in children, as well as in adults, is associated with serious consequences, including increased risk of mortality, kidney failure, cardiovascular disease, mineral bone disorder, and poor nutrition. Moreover, children have a longer life expectancy with a longer time to manifest complications related with CKD. Comorbidities of CKD may also lead to complications that include impairments in physical and psychosocial development in children $^{3,4)}$. Therefore, pediatric CKD requires a higher cost of care per individual than that in adult $\mathrm{CKD}^{5}$.

Slowing down the progression of kidney function decline in children with CKD is important since CKD with declined renal function (estimated glomerular filtration rate (eGFR) $\leq 60 \mathrm{~mL} / \mathrm{min} / 1.73 \mathrm{~m}^{2}$ body surface area for more than 3 months) has no cure. Identifying risk factors for the progression of CKD may help clinicians recognize the risk factors earlier and initiate preventive interventions for $\mathrm{CKD}$ and its attendant comorbidities, as well as monitor for complications. Prospective cohort studies have been conducted to understand CKD progression and outcomes in children. These studies included Chronic Kidney Disease in Children (CKiD) in North America ${ }^{6}$, Cardiovascular Comorbidity in Children with Chronic Kidney Disease (4C) in European countries ${ }^{7}$, and KoreaN cohort study for Outcome in patients With Pediatric Chronic Kidney Disease (KNOW-PedCKD) in Korea ${ }^{8)}$ (Table 1). 
In this review, the factors that affect the progression of pediatric CKD, which were reported by previous studies, will be reviewed.

\section{Non-modifiable risk factors}

\section{Primary kidney disease}

Primary kidney disease is an important predictor of CKD progression in children. Congenital anomalies of the kidney and urinary tract (CAKUT) are the most common cause of pediatric CKD. Children with CAKUT experience a slower progression of CKD than those with other causes, resulting in a lower proportion of CAKUT in the population of children with kidney failure ${ }^{2)}$. The kidney survival analysis based on data from the European Renal Association-European Dialysis and Transplant Association (ERAEDTA) Registry showed that patients with CAKUT progressed to kidney failure at a median age of 31 years ${ }^{9)}$. In the study, more than two-thirds of patients with CAKUT notably developed kidney failure in the adult age, and 50\% did not require kidney replacement therapy before the fourth decade of life.

Glomerulopathy in children is a result of various disorders including genetic and autoimmune diseases. It causes inflammation and damage to the glomeruli, the filtering units of the kidney, resulting in a rapid decrease in kidney function. According to the CKiD study, patients with glomerulopathy progressed to a composite renal event of kidney failure and/or 50\% reduction in GFR after a median follow-up of 3.7 years, which was faster than in patients with non-glomerulopathy $(5.2 \text { years })^{10}$. In a retrospective cohort study of children with CKD stages 2-4, patients with glomerular diseases were found to progress more quickly to kidney failure than those with other primary kidney diseases, with the adjusted hazard ratio of 2.9
(95\% confidence interval, 1.4-6.1) ${ }^{11)}$.

\section{CKD stage}

Previous studies reported baseline GFR as the major risk factor for CKD progression in children ${ }^{10-12)}$. In 2012, the Kidney Disease: Improving Global Outcomes (KDIGO) developed a CKD classification system according to kidney disease causes, GFR category, and albuminuria category. Large-scale observational cohort study, including the CKiD study and the Effect of Strict Blood Pressure Control and ACE inhibition on Chronic Renal Failure Progression in Pediatric Patients (ESCAPE) trial, classified pediatric patients with CKD according to three risk factors: GFR category developed by KDIGO, proteinuria, and glomerular versus non-glomerular diseases ${ }^{13)}$. This study showed that median times to a composite kidney event ranged from longer than 10 years for CKD stages 2 to $3 \mathrm{a}$ and urine protein/creatinine ratio (UPCR) of $<0.5 \mathrm{mg} / \mathrm{mg}$ to 0.8 years for CKD stage 4 and UPCR of $>2 \mathrm{mg} / \mathrm{mg}$.

\section{Perinatal factors}

Nephrogenesis commences at 5 weeks of gestation and reaches its peak velocity between 20 and 28 weeks of gestation. Therefore, in preterm infants born with immature kidneys during the period between 20 and 28 weeks, postnatal renal maturation accelerated after birth, with abnormal morphology of nephrons ${ }^{14)}$. The CKiD study reported that an abnormal birth history, including low birth weight, small for gestational age (SGA), and prematurity, is more common in children with CKD than those in the general population ${ }^{15}$. A nationwide cohort study in Sweden revealed that preterm and early-term birth are strong risk factors for the development of CKD from childhood to mid-adulthood ${ }^{16)}$. In the Norway Birth Registry, low birth weight subjects had an adjusted hazard ratio for kidney failure of 1.61 (95\% confidence interval, 1.4-1.98) compared

Table 1. Prospective cohort studies for children with chronic kidney disease

\begin{tabular}{lcccccc}
\hline & Country & CKD stage & $\begin{array}{c}\text { Age } \\
\text { (years) }\end{array}$ & Number & $\begin{array}{c}\text { Follow-up period } \\
\text { (years) }\end{array}$ & Primary outcome \\
\hline CKiD & North America & $2-4$ & $0.5-17$ & 1,043 & 15 & A decline of eGFR by $\geq 50 \%$ or KRT \\
$4 C$ & European countries & $3-5$ & $6-17$ & 688 & 5 & Cardiovascular comorbidity \\
KNOW-PedCKD & Korea & $1-5$ & $<20$ & 458 & 10 & A decline of eGFR by $\geq 50 \%$ or KRT \\
\hline
\end{tabular}

CKD, chronic kidney disease; CKiD, Chronic Kidney Disease in Children; eGFR, estimated glomerular filtration rate; KRT, kidney replacement therapy; 4C, Cardiovascular Comorbidity in Children with Chronic Kidney Disease; KNOW-PedCKD, KoreaN cohort study for Outcome in patients With Pediatric Chronic Kidney Disease. 
with those without low birth weight ${ }^{17)}$. This study also showed that subjects with at least two of the three risk factors, including low birth weight, SGA, or preterm birth, have an increased risk for kidney failure. However, evidence that perinatal factors are independent risk factors for the kidney function decline in children with CKD is little. In the CKiD study, low birth weight, SGA, and premature birth were not predictors of more rapid CKD progression ${ }^{10)}$.

\section{Modifiable risk factors}

\section{Proteinuria}

The presence of proteinuria constitutes a sign of kidney damage, and heavy proteinuria predicts a rapid kidney function decline. Experimental evidence supports the crucial role of proteinuria in accelerating the progression of kidney disease to kidney failure through multiple pathways $^{18)}$. Urinary proteins themselves can elicit pro-inflam. matory and profibrotic effects that directly contribute to chronic tubulointerstitial damage. This tubulointerstitial injury is one of the mediators that lead to CKD progression.

In a cross-sectional analysis of the CKiD study, a decrease in GFR was associated with an increase in UPCR ${ }^{19}$. Warady et al. revealed that times to either a $50 \%$ decline in GFR or the initiation of kidney replacement therapy were significantly shorter with nephrotic-range proteinuria among children with glomerular and non-glomerular CKD ${ }^{10)}$. Fuhrman et al. showed that children with proteinuria of $\geq 0.2 \mathrm{mg} / \mathrm{mg}$ and albuminuria of $\geq 30 \mathrm{mg} / \mathrm{g}$ had a mean eGFR that was $16 \mathrm{~mL} / \mathrm{min} / 1.73 \mathrm{~m}^{2}$ lower than those without proteinuria and albuminuria ${ }^{20}$. The ESCAPE trial demonstrated that higher levels of proteinuria were associated with a more rapid decline in $\mathrm{GFR}^{21)}$.

The renin-angiotensin system (RAS) blockade is known to reduce the progressive deterioration of kidney function in patients with CKD through the reduction of blood pressure and proteinuria. Most clinical trials and cohort studies supported the use of RAS blockers in patients with mild to moderate $\mathrm{CKD}^{21-23)}$. Recently, 4C study showed that GFR declined more rapidly after discontinuation of RAS inhibition compared with that during RAS inhibition (-3.9vs. -1.5 $\mathrm{mL} / \mathrm{min} / 1.73 \mathrm{~m}^{2}$ per year $)^{24)}$. However, the renoprotective effect of RAS blockade in non-glomerulopathy remains controversial. In the ItalKid Project, angiotensin-converting enzyme inhibitor treatment did not significantly modify the naturally progressive course of hypodysplastic nephropathies in children ${ }^{25}$. Because this study did not have any information concerning proteinuria, it was not sure whether RAS blockade provided an anti-proteinuric effect in children with non-glomerulopathy ${ }^{25}$. On the other hand, the ESCAPE trial showed that RAS inhibition resulted in reducing urinary protein excretion and lowering blood pressure in both glomerulopathy and non-glomerulopathy ${ }^{21)}$.

\section{Hypertension}

The kidney is a major site for target organ damage of hypertension. Systemic hypertension and glomerular hyperfiltration lead to progressive nephron damage ${ }^{26)}$. Flynn et al. demonstrated that $54 \%$ of pediatric patients with CKD were hypertensive, which was defined as either blood pressure of $>95$ th percentile or as self-reported hypertension plus current treatment with hypertensive medications ${ }^{27)}$. The study group conducted a follow-up analysis 10 years later to compare blood pressure control over two time periods among participants enrolled in 2005-2008 and $2010-2013^{28)}$. In this study, no significant differences were found in hypertension between the two time periods, suggesting that hypertension remains undertreated and under-recognized in children with CKD. Warady et al. revealed that elevated blood pressure was associated with a significant reduction in time to kidney events in patients with both glomerular (67\% reduction) and non-glomerular disease $(38 \% \text { reduction })^{10)}$. This finding emphasized the importance of aggressive BP control, particularly in patients with glomerular causes of CKD.

The ESCAPE trial showed that intensified blood pressure control conferred a substantial benefit regarding kidney function among children with CKD stages $2-4^{21)}$. The trial was designed to compare intensified blood pressure control (target $<50$ th percentile) with conventional control (50th90th percentile) using an angiotensin-converting enzyme inhibitor. Based on the results of this trial, the KDIGO guideline recommends that the blood pressure treatment target for children with CKD is systolic and diastolic blood pressure of less than the 50th percentile for gender, age, and height $^{29)}$. 


\section{Dyslipidemia}

The prevalence of dyslipidemia in children with CKD is high, being present in $39 \%-65 \%$ of patients ${ }^{30}$. The KNOWPedCKD study reported that $61.5 \%$ of pediatric patients with CKD stages 1-5 had dyslipidemia, and CKD stage $\geq 3 \mathrm{~b}$ had a significantly increased risk for high triglyceride level ${ }^{31)}$. In the CKiD study including children with CKD stages $2-4,45 \%$ of patients with CKD had dyslipidemia, and lower GFR was associated with dyslipidemia ${ }^{32)}$.

While dyslipidemia is a well-known cardiovascular disease risk factor commonly found in children as well as in adults, the relationship between dyslipidemia and CKD progression in children is uncertain. Warady et al. reported that dyslipidemia was significantly related to CKD progression in children with non-glomerulopathy, but not in those with glomerulopathy ${ }^{10)}$. Longitudinal analysis in the CKiD study showed that decreases in GFR during follow-up were significantly associated with concomitant decreases of HDL cholesterol in children with non-glomerular CKD and increases of non-HDL cholesterol in children with glomerular $\mathrm{CKD}^{33)}$. In this study, dyslipidemia was also associated with concomitant increases in proteinuria and body mass index. Future studies are needed to clarify the relationship between CKD progression and dyslipidemia in children with CKD.

Dyslipidemia is managed through therapeutic lifestyle changes and pharmacologic treatment. Although the evidence is weak on lifestyle modifications are effective to improve dyslipidemia in children with CKD, these are unlikely to cause harm and can promote better health ${ }^{34)}$. Statins and ezetimibe are approved by the USA and Korean Food and Drug Administration to treat dyslipidemia in the pediatric population. However, the 2013 KDIGO guideline does not recommend the lipid-lowering agent as the first-line treatment in children under 18 years with CKD due to the lack of evidence ${ }^{35)}$.

\section{Hyperuricemia}

Hyperuricemia is associated with the development and progression of CKD. Experimental studies supported that hyperuricemia plays a role in CKD progression through direct kidney injury, including oxidative stress, endothelial cell dysfunction, and epithelial-to-mesenchymal transition of tubular cell ${ }^{36)}$. Rodenbach et al. reported that hyperuricemia is an independent risk factor for the faster progres- sion of CKD in children. In this study, pediatric patients with CKD with uric acid levels of 5.5 to 7.5 or $>7.5 \mathrm{mg} / \mathrm{dL}$ had $17 \%$ or $38 \%$ shorter times to CKD progression, respectively, compared with those with uric acid levels of $<5.5$ $\mathrm{mg} / \mathrm{dL}^{37)}$. The Taiwan Pediatric Renal Collaborative Study showed that hyperuricemia significantly increased the risk of CKD progression in children with CKD because of a structural abnormality or genetic disease ${ }^{12)}$.

Treating asymptomatic hyperuricemia to slow down the progression of CKD is controversial, given the conflicting results in several clinical studies ${ }^{36)}$. A meta-analysis study concluded that data suggesting uric acid-lowering therapy may prevent CKD progression is limited, and larger clinical trials are needed to evaluate the benefits and risks of uric acid-lowering therapy in $\mathrm{CKD}^{38)}$. In a prospective cohort study in adults, hyperuricemia appears to be an independent risk factor for CKD progression, but urate-lowering agents did not show a renoprotective effect ${ }^{39)}$.

\section{Anemia}

Anemia is a common complication of CKD and is associated with several clinical consequences, including mortality, cardiovascular morbidity, and growth failure ${ }^{40,41)}$. Two prospective cohort studies for children with CKD showed that $40 \%-45 \%$ of patients had anemia and the hemoglobin level decreases as GFR declines ${ }^{42,43}$. Anemia and resulting tissue hypoxia could increase endothelial injury and stimulate the release of profibrotic cytokines. GFR declined more rapidly in adolescent patients with CKD with significant anemia. In the CKiD study, anemia was associated with an accelerated decline of $7.8 \mathrm{~mL} / \mathrm{min} / 1.73 \mathrm{~m}^{2}$ in adolescents with CKD aged 11-18 years compared with the decline rate in those without anemia ${ }^{44)}$. Warady et al. reported that time to the composite renal event was significantly shorter with anemia by $45 \%$ among children with non-glomerular $\mathrm{CKD}^{10)}$.

In the KNOW-Ped CKD study, only $21.6 \%$ and $36.6 \%$ of children with anemia were treated with erythropoietinstimulating agent (ESA) and iron supplementation treatment, respectively ${ }^{43}$. This finding suggests the importance of identifying anemia and iron deficiency and actively correcting these in pediatric patients with $\mathrm{CKD}$. In a randomized controlled study in adults with predialysis CKD, early treatment of ESA targeting at a higher hemoglobin 
level significantly slowed the progression of CKD and delayed the initiation of kidney replacement therapy ${ }^{45}$. However, high serum erythropoietin level is associated with the risk of cardiovascular events in adults ${ }^{46}$. Although the question of appropriate target hemoglobin levels in children remains under debate, the KDIGO guideline recommends that $\mathrm{Hb}$ targets with ESA treatment should be kept within the range of $11.0-12.0 \mathrm{~g} / \mathrm{dL}^{47)}$.

\section{Conclusions}

To date, several risk factors for the progression of pediatric CKD are known. Modifiable risk factors for CKD progression in children should be identified early and treated adequately. Recognition of non-modifiable risk factors is also important since patients at high risk could particularly benefit from strict control of remediable risk factors including hypertension and proteinuria. Developing a prediction model for the progression of CKD is needed to support clinical decision making. Additionally, further research is necessary to determine the effects of risk factor interventions on the progression of CKD in children.

\section{Conflict of interest}

No potential conflict of interest relevant to this article was reported.

\section{ORCID}

Yo Han Ahn https://orcid.org/0000-0002-9349-4366

Hee Gyung Kang https://orcid.org/0000-0001-83235320

Il-Soo Ha http://orcid.org/0000-0001-5428-6209

\section{References}

1. Becherucci F, Roperto RM, Materassi M, Romagnani P. Chronic kidney disease in children. Clin Kidney J 2016;9:583-91.

2. Harambat J, van Stralen KJ, Kim JJ, Tizard EJ. Epidemiology of chronic kidney disease in children. Pediatr Nephrol 2012;27:36373.

3. Baek HS, Kang HG, Choi HJ, Cheong HI, Ha IS, Han KH, et al. Health-related quality of life of children with pre-dialysis chronic kidney disease. Pediatr Nephrol 2017;32:2097-105.

4. Kang NR, Ahn YH, Park E, Choi HJ, Kim SH, Cho H, et al. Mental health and psychosocial adjustment in pediatric chronic kidney disease derived from the KNOW-Ped CKD study. Pediatr Nephrol 2019;34:1753-64.

5. Saran R, Robinson B, Abbott KC, Agodoa LY, Albertus P, Ayanian J, et al. US Renal Data System 2016 annual data report: epidemiology of kidney disease in the United States. Am J Kidney Dis 2017;69(3 Suppl 1):A7-A8.

6. Atkinson MA, Ng DK, Warady BA, Furth SL, Flynn JT. The CKiD study: overview and summary of findings related to kidney disease progression. Pediatr Nephrol 2021;36:527-38.

7. Querfeld U, Anarat A, Bayazit AK, Bakkaloglu AS, Bilginer Y, Caliskan $\mathrm{S}$, et al. The Cardiovascular Comorbidity in Children with Chronic Kidney Disease (4C) study: objectives, design, and methodology. Clin J Am Soc Nephrol 2010;5:1642-8.

8. Kang HG, Choi HJ, Han KH, Kim SH, Cho HY, Cho MH, et al. KNOW-Ped CKD (KoreaN cohort study for outcomes in patients with pediatric CKD): Design and methods. BMC Nephrol 2016;17: 35.

9. Wuhl E, van Stralen KJ, Verrina E, Bjerre A, Wanner C, Heaf JG, et al. Timing and outcome of renal replacement therapy in patients with congenital malformations of the kidney and urinary tract. Clin J Am Soc Nephrol 2013;8:67-74.

10. Warady BA, Abraham AG, Schwartz GJ, Wong CS, Munoz A, Betoko $A$, et al. Predictors of rapid progression of glomerular and nonglomerular kidney disease in children and adolescents: the Chronic Kidney Disease in Children (CKiD) cohort. Am J Kidney Dis 2015;65:878-88.

11. Cerqueira DC, Soares CM, Silva VR, Magalhaes JO, Barcelos IP, Duarte $M G$, et al. A predictive model of progression of CKD to ESRD in a predialysis pediatric interdisciplinary program. Clin J Am Soc Nephrol 2014;9:728-35.

12. Chiou YY, Lin CY, Chen MJ, Chiou YH, Wang YF, Wang HH, et al. Etiology and pediatric chronic kidney disease progression: Taiwan Pediatric Renal Collaborative Study. J Formos Med Assoc 2016; 115:752-63.

13. Furth SL, Pierce C, Hui WF, White CA, Wong CS, Schaefer F, et al. Estimating time to ESRD in children with CKD. Am J Kidney Dis 2018;71:783-92.

14. Sutherland MR, Gubhaju L, Moore L, Kent AL, Dahlstrom JE, Horne $\mathrm{RS}$, et al. Accelerated maturation and abnormal morphology in the preterm neonatal kidney. J Am Soc Nephrol 2011;22:1365-74.

15. Greenbaum LA, Munoz A, Schneider MF, Kaskel FJ, Askenazi DJ, Jenkins $\mathrm{R}$, et al. The association between abnormal birth history and growth in children with CKD. Clin J Am Soc Nephrol 2011;6: 14-21.

16. Crump C, Sundquist J, Winkleby MA, Sundquist K. Preterm birth 
and risk of chronic kidney disease from childhood into midadulthood: national cohort study. BMJ 2019;365:11346.

17. Gjerde A, Lillas BS, Marti HP, Reisaeter AV, Vikse BE. Intrauterine growth restriction, preterm birth and risk of end-stage renal disease during the first 50 years of life. Nephrol Dial Transplant 2020;35:1157-63.

18. Gorriz JL, Martinez-Castelao A. Proteinuria: detection and role in native renal disease progression. Transplant Rev (Orlando) 2012; 26:3-13.

19. Wong CS, Pierce CB, Cole SR, Warady BA, Mak RH, Benador NM, et al. Association of proteinuria with race, cause of chronic kidney disease, and glomerular filtration rate in the chronic kidney disease in children study. Clin J Am Soc Nephrol 2009;4:812-9.

20. Fuhrman DY, Schneider MF, Dell KM, Blydt-Hansen TD, Mak R, Saland JM, et al. Albuminuria, proteinuria, and renal disease progression in children with CKD. Clin J Am Soc Nephrol 2017;12: 912-20.

21. Group ET, Wuhl E, Trivelli A, Picca S, Litwin M, Peco-Antic A, et al. Strict blood-pressure control and progression of renal failure in children. N Engl J Med 2009;361:1639-50.

22. Abraham AG, Betoko A, Fadrowski JJ, Pierce C, Furth SL, Warady BA, et al. Renin-angiotensin II-aldosterone system blockers and time to renal replacement therapy in children with CKD. Pediatr Nephrol 2017;32:643-9.

23. Coppo R, Peruzzi L, Amore A, Piccoli A, Cochat P, Stone R, et al. IgACE: a placebo-controlled, randomized trial of angiotensinconverting enzyme inhibitors in children and young people with IgA nephropathy and moderate proteinuria. J Am Soc Nephrol 2007:18:1880-8.

24. van den Belt SM, Heerspink HJL, Kirchner M, Gracchi V, ThurnValsassina D, Bayazit AK, et al. Discontinuation of RAAS inhibition in children with advanced CKD. Clin J Am Soc Nephrol 2020;15: 625-32.

25. Ardissino G, Vigano S, Testa S, Dacco V, Paglialonga F, Leoni A, et al. No clear evidence of ACEi efficacy on the progression of chronic kidney disease in children with hypodysplastic nephropathyreport from the ItalKid Project database. Nephrol Dial Transplant 2007;22:2525-30.

26. Griffin KA. Hypertensive kidney injury and the progression of chronic kidney disease. Hypertension 2017;70:687-94.

27. Flynn JT, Mitsnefes M, Pierce C, Cole SR, Parekh RS, Furth SL, et al. Blood pressure in children with chronic kidney disease: a report from the Chronic Kidney Disease in Children study. Hypertension 2008:52:631-7.

28. Barletta GM, Pierce C, Mitsnefes M, Samuels J, Warady BA, Furth $S$, et al. Is blood pressure improving in children with chronic kidney disease? A period analysis. Hypertension 2018;71:444-50.

29. The Kidney Disease: Improving Global Outcomes (KDIGO) CKD Work Group. KDIGO clinical practice guideline for the management of blood pressure in chronic kidney disease. Kidney Int Suppl 2012;2:337-414.

30. Khurana M, Silverstein DM. Etiology and management of dys- lipidemia in children with chronic kidney disease and end-stage renal disease. Pediatr Nephrol 2015;30:2073-84.

31. Baek HS, Kim SH, Kang HG, Choi HJ, Cheong HI, Ha IS, et al. Dyslipidemia in pediatric CKD patients: results from KNOW-PedCKD (KoreaN cohort study for Outcomes in patients With Pediatric CKD). Pediatr Nephrol 2020;35:1455-61.

32. Saland JM, Pierce CB, Mitsnefes MM, Flynn JT, Goebel J, Kupferman JC, et al. Dyslipidemia in children with chronic kidney disease. Kidney Int 2010;78:1154-63.

33. Saland JM, Kupferman JC, Pierce CB, Flynn JT, Mitsnefes MM, Warady BA, et al. Change in dyslipidemia with declining glomerular filtration rate and increasing proteinuria in children with CKD. Clin J Am Soc Nephrol 2019;14:1711-8.

34. Khurana M, Silverstein DM. Etiology and management of dyslipidemia in children with chronic kidney disease and end-stage renal disease. Pediatr Nephrol 2015;30:203-84.

35. Kidney Disease: Improving Global Outcomes (KDIGO) Lipid Work Group. KDIGO clinical practice guideline for lipid management in chronic kidney disease. Kidney Int Suppl 2013;3:259-305.

36. Johnson RJ, Nakagawa T, Jalal D, Sanchez-Lozada LG, Kang DH, Ritz E. Uric acid and chronic kidney disease: which is chasing which? Nephrol Dial Transplant 2013;28:2221-8.

37. Rodenbach KE, Schneider MF, Furth SL, Moxey-Mims MM, Mitsnefes MM, Weaver DJ, et al. Hyperuricemia and progression of CKD in children and adolescents: the Chronic Kidney Disease in Children (CKiD) cohort study. Am J Kidney Dis 2015;66:984-92.

38. Sampson AL, Singer RF, Walters GD. Uric acid lowering therapies for preventing or delaying the progression of chronic kidney disease. Cochrane Database Syst Rev 2017;10:CD009460.

39. Oh TR, Choi HS, Kim CS, Bae EH, Ma SK, Sung SA, et al. Hyperuricemia has increased the risk of progression of chronic kidney disease: propensity score matching analysis from the KNOWCKD study. Sci Rep 2019;9:6681.

40. Atkinson MA, Furth SL. Anemia in children with chronic kidney disease. Nat Rev Nephrol 2011;7:635-41.

41. Kim JY, Lee Y, Kang HG, Ha IS, Cheong HI, Choi HJ, et al. Left-ventricular diastolic dysfunction in Korean children with chronic kidney disease: data from the KNOW-Ped CKD study. BMC Nephrol 2020;21:533.

42. Fadrowski JJ, Pierce CB, Cole SR, Moxey-Mims M, Warady BA, Furth SL. Hemoglobin decline in children with chronic kidney disease: baseline results from the chronic kidney disease in children prospective cohort study. Clin J Am Soc Nephrol 2008;3:45762.

43. Lee KH, Park E, Choi HJ, Kang HG, Ha IS, Cheong HI, et al. Anemia and iron deficiency in children with chronic kidney disease (CKD): Data from the Know-Ped CKD study. J Clin Med 2019;8:152.

44. Furth SL, Cole SR, Fadrowski JJ, Gerson A, Pierce CB, Chandra M, et al. The association of anemia and hypoalbuminemia with accelerated decline in GFR among adolescents with chronic kidney disease. Pediatr Nephrol 2007;22:265-71.

45. Gouva C, Nikolopoulos P, Ioannidis JP, Siamopoulos KC. Treating 
www.chikd.org

anemia early in renal failure patients slows the decline of renal function: a randomized controlled trial. Kidney Int 2004;66:75360.

46. Garimella PS, Katz R, Patel KV, Kritchevsky SB, Parikh CR, Ix JH, et al. Association of serum erythropoietin with cardiovascular events, kidney function decline, and mortality: the Health Aging and Body Composition study. Circ Heart Fail 2016;9:e002124.

47. The Kidney Disease: Improving Global Outcomes (KDIGO) CKD Work Group. KDIGO clinical practice guideline for anemia in chronic kidney disease. Kidney Int Suppl 2012;2:279-335. 